Ulrike Einhorn-Stoll, Hanna Kastner, Alexandra Urbisch, Lothar W. Kroh, Stephan Drusch

\title{
Thermal degradation of citrus pectin in low-moisture environment - Influence of acidic and alkaline pre-treatment
}

Journal article | Accepted manuscript (Postprint)

This version is available at https://doi.org/10.14279/depositonce-9850

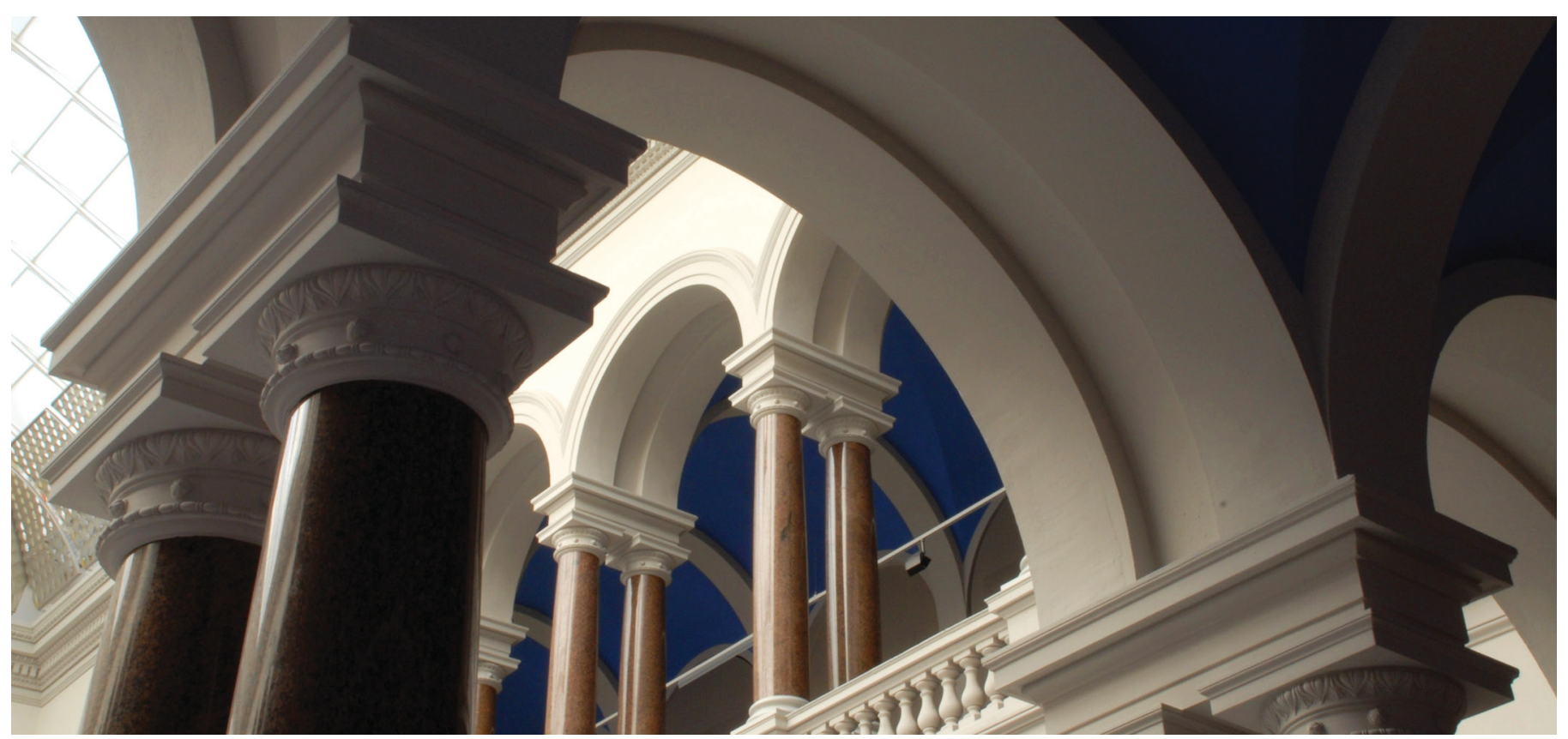

Einhorn-Stoll, U., Kastner, H., Urbisch, A., Kroh, L. W., \& Drusch, S. (2019). Thermal degradation of citrus pectin in low-moisture environment - Influence of acidic and alkaline pre-treatment. Food Hydrocolloids, 86, 104-115. https://doi.org/10.1016/j.foodhyd.2018.02.030 


\section{Thermal degradation of citrus pectin powder - Influence of acidic and alkaline pre-treatment}

Ulrike Einhorn-Stoll ${ }^{1}$, Hanna Kastner ${ }^{1}$, Alexandra Urbisch ${ }^{2}$, Lothar W. Kroh², Stephan Drusch ${ }^{1}$

${ }^{1}$ Technische Universität Berlin, Food Technology and Food Material Sciences, Germany

${ }^{2}$ Technische Universität Berlin, Food Chemistry and Analytics, Germany

\section{Abstract}

Pectin powder is degraded during storage and transport by demethoxylation and depolymerisation. The degradation mechanisms and especially the influence of pre-treatments on the degradation reactions are not completely understood. In this study, commercial citrus pectin was modified by either acidic or alkaline demethoxylation. The modified pectins, as well as the commercial pectin, were thermally degraded during four weeks of storage at $60{ }^{\circ} \mathrm{C}$ and $80 \%$ relative humidity. Demethoxylation and depolymerisation as well as colour alterations were examined during degradation, and the course of the reactions was monitored.

It was found that the type of pre-treatment during modification determined the material properties and, thus, the water uptake of the modified pectin powders. The resulting water availability in the samples was crucial to the extent of demethoxylation and to the type and intensity of depolymerisation since some of these reactions competed for the water in the climate chamber. The pre-treatment also determined the content of neutral sugars and sodium ions of the modified pectins. High contents of these components limited the extent of degradation in different ways. A previously assumed third depolymerisation mechanism of pectins, beside backbone hydrolysis and ß-elimination, was confirmed. 


\section{Introduction}

Pectin is one of the most popular food ingredients worldwide and, in contrast to other hydrocolloids, has an excellent image. Commercial pectins are produced as powders mainly in Europe (Germany, Denmark, France) and, to a lower extent, in Latin America and China. They are sold and applied worldwide and have to be transported and stored for several weeks or months, often under unfavorable environmental conditions. Such storage may cause pectin degradation (Einhorn-Stoll, Benthin, Zimathies, Görke, \& Drusch, 2015a; Einhorn-Stoll, Kastner, \& Drusch, 2014; Einhorn-Stoll \& Kunzek, 2009; Padival, Ranganna, \& Manjrekar, 1981). Pectin is degraded also by heatprocessing as was found in pectin-containing plant tissues and in food products such as fruit juices, purees and jams (for instance Christiaens et al., 2011; Ibarz, Garza, \& Pagán, 2008; Sila, Smout, Elliot, van Loey, \& Hendrickx, 2006; Jayaraman \& Van Buren, 1972). The thermal degradation causes non-enzymatic browning and has an impact on the product quality.

Pectin degradation has been investigated in the last decades mainly in model pectin solutions. Several groups tested the influence of external factors such as temperature and $\mathrm{pH}$ and of internal parameters such as degree of methoxylation (DM) and of ions (for instance Bornik \& Kroh, 2013; Diaz, Anthon, \& Barrett, 2007; Fraeye et al., 2007; Krall \& McFeeters, 1998; Renard \& Thibault, 1996; Axelos \& Branger, 1993; Sajjaanantakul, Van Buren, \& Downing, 1993; Kravtchenko, Arnould, Voragen, \& Pilnik, 1992; Voragen, Schols, \& Pilnik, 1988; Thibault, 1983; Van Buren, 1979; Keijbets \& Pilnik, 1974; BeMiller \& Kumari, 1972). Most works did, however, not consider a possible influence of pectin pre-treatments or of different production details on the thermal degradation reactions. For instance, demethoxylation is possible by enzymatic or by chemical treatments at low $\mathrm{pH}$ (acidic demethoxylation) as well as at high $\mathrm{pH}$ (alkaline demethoxylation), what is leading to considerable differences in pectin composition and material properties (Einhorn-Stoll, Kastner, Hecht, Zimathies, \& Drusch, 2015b).

The knowledge of thermal pectin degradation in solutions may only to some extend be transferred to pectin powder. In comparison to solutions, dry pectin powder is assumed to be in a relatively stable state. Nevertheless, it is a highly reactive system, especially at high temperature and humidity. First investigations on the influence of long-term storage on dry pectin powders have been reported by Padival et al. (1981). They stored different low-methoxylated pectin (LMP) samples at room temperature for up to 12 months and found a certain degradation by demethoxylation and depolymerisation. Einhorn-Stoll and Kunzek (2009) accelerated the degradation of different labprepared high-methoxylated pectin (HMP) and LMP powders by storing samples in a climate chamber at $50-60{ }^{\circ} \mathrm{C}$ and $60-80 \%$ relative humidity for two weeks. Beside demethoxylation and depolymerisation, all samples showed a visible browning. Discussing the possible degradation mechanisms, an additional third depolymerisation reaction beside the well-known backbone hydrolysis and ß-elimination was assumed. Based on these results, the degradation of commercial 
pectins of varying types and from different suppliers was examined (Einhorn-Stoll, et al, 2015a; Einhorn-Stoll et al, 2014). According to all these works, the intensity of the thermal pectin degradation was dependent on not only temperature and relative humidity in the system but also on the pectin type and molecular parameters. Padival et al. (1981) described a slightly stronger degradation of acidic treated compared to alkaline treated modified LMP. Einhorn-Stoll \& Kunzek (2009) found an influence of the initial DM of the modified pectin. Since pectins with similar molecular parameters such as DM or intrinsic viscosity $([\eta])$ but from various suppliers differed strongly in their degradation behavior, Einhorn-Stoll et al. (2015a, 2014) additionally assumed an impact of the raw material (type and geographic source of citrus fruits) and of the production process as described before for other food powder properties (Cuq, Rondet, \& Abecassis, 2011). As a consequence, for a systematic investigation modified pectin types should be prepared by different procedures from one single initial sample.

The presented study shall examine the thermal degradation of pectin powder (thermolysis) more detailed and in dependence on different pre-treatments applied for pectin modification. It is using citrus pectin since about $80 \%$ of all industrially applied pectins are of citrus origin. In comparison to the previous studies, the storage in the climate chamber was extended to four weeks and not only the final but also intermediate states have been examined. The aims were (1) to investigate the influence of type of pre-treatment and intensity of pectin modifications on the thermal degradation of pectin powder, (2) to study the course of these reactions and (3) to understand the complex mechanisms of the involved degradation reaction types.

\section{Theoretical background}

In order to understand the degradation reactions, it is necessary to remember the pectin molecular structure as described in detail by several authors (for instance Schols and Voragen, 2002; Thakur, Singh, \& Handa, 1997). In the most common model, pectin consists of a backbone of galacturonic acid molecules (GalA), which are connected via glycosidic linkages and are partly methylesterified at C6 (homogalacturonan section). The GalA is partly linked with rhamnose molecules (rhamnogalacturonan section) to which neutral sugar side chains are bound. These chains contain for instance D-galactose (Gal), D-glucose (Glu) or L-arabinose (Ara) as shown in Fig. 1. According to the DM of the GalA, the pectins are divided into HMP and LMP.

In the last decades, many authors have intensively examined the influence of the reaction conditions $\mathrm{pH}$ and temperature and the impact of pectin DM on thermal pectin degradation in solutions with regard to possible mechanisms, interactions and reaction products. They found that the typical degradation reactions are demethoxylation as well as depolymerisation by backbone 
hydrolysis and / or ß-elimination (Fig. 1). The dominating reaction types depended on several factors:

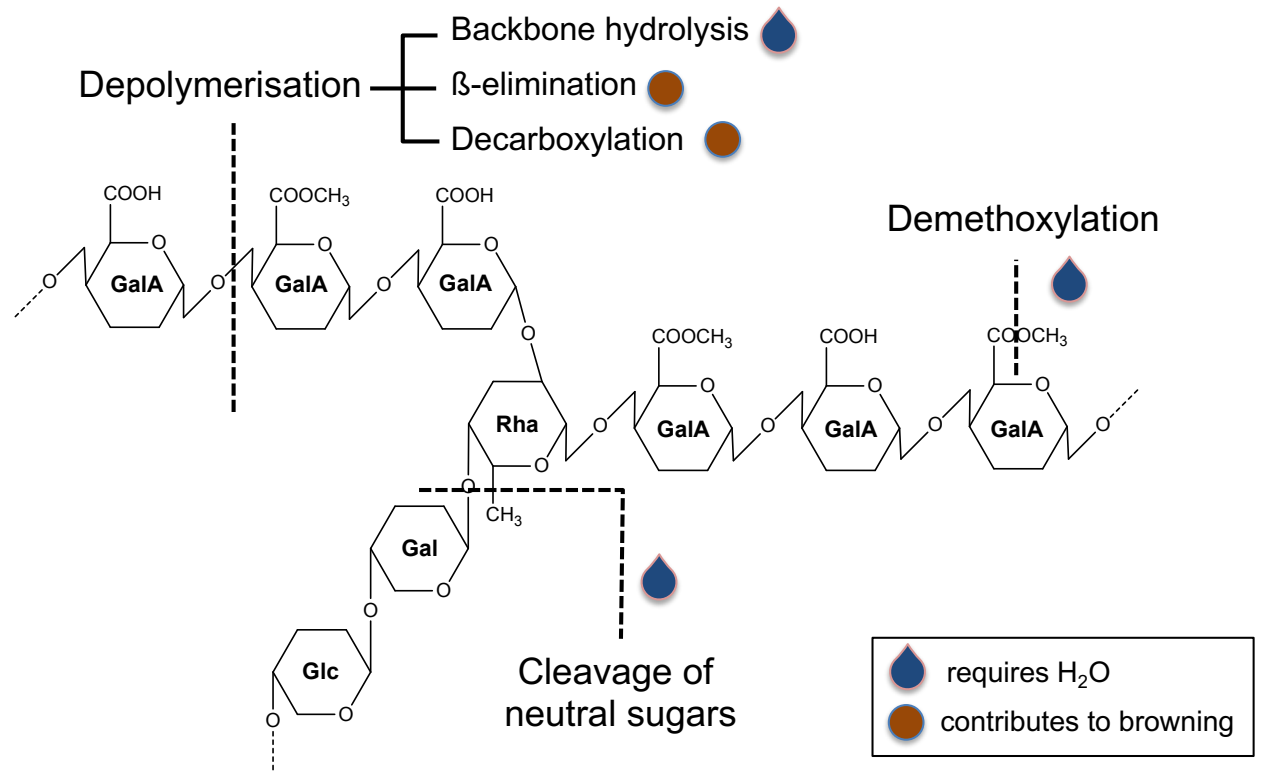

Fig. 1 Pectin structure and possible reactions during degradation.

- High DM favours ß-elimination since adjoining ester groups are necessary for this reaction. Thus, demethoxylation indirectly reduces a parallel depolymerisation by ß-elimination (Fraeye et al., 2007; Diaz et al., 2007; Krall \& McFeeters, 1998; Van Buren, 1979; Keijbets \& Pilnik, 1974; Albersheim, Neukom, \& Deuel, 1960).

- Low DM promotes backbone hydrolysis. Pectin demethoxylation indirectly enhances this depolymerisation reaction (Fraeye et al., 2007; Diaz et al., 2007; Krall \& McFeeters, 1998; Timell, Enterman, Spencer, \& Solters, 1965).

- Substituents bound at C-5 of the GalA have a considerable influence on backbone hydrolysis. Glycosidic linkages between glycosiduronic acids (-COOH at $\mathrm{C}-5$, such as galacturonic acid) are more resistant to acid hydrolysis than glycosidic linkages between glycopyranosides (neutral sugars) because of an inductive effect of the carboxyl group at C-5 and / or because of conformational reasons (Van Buren, 1979; Bemiller \& Doyle, 1971; Timell et al., 1965). It was partly assumed, therefore, that backbone hydrolysis takes place mainly in the rhamnogalacturonan fraction (Van Buren, 1979). The hydrolysis resistance of the linkages in the backbone is additional increased by bound methoxyl groups $\left(-\mathrm{COCH}_{3}\right)$ instead of carboxyl groups at C-5 in pectins with high DM.

- Low $\mathrm{pH}$ around or below the $\mathrm{pK}_{\mathrm{a}}$ of pectin (at $\mathrm{pH}$ 3.5) favours acidic demethoxylation and acidic backbone hydrolysis. The reaction rate of acidic demethoxylation is higher than that of acidic backbone hydrolysis (Timell et al., 1965). pH above 6 promotes alkaline demethoxylation 
(saponification) and ß-elimination. In the intermediate range all these reactions have been detected (Fraeye et al., 2007; Diaz et al., 2007; Krall \& McFeeters, 1998) to different extents.

- Neutral sugars in side chains are cleaved hydrolytically, especially at acidic $\mathrm{pH}$. This reaction is favoured over backbone hydrolysis (Axelos \& Branger, 1993; Van Buren, 1979).

- Cations are assumed to support the degradation by ß-elimination (Sajjaanantakul et al., 1993; Keijbets \& Pilnik, 1974) but have no effect on backbone hydrolysis (Krall \& McFeeters, 1998).

- High temperature accelerates all degradation reactions but in particular ß-elimination (Fraeye et al., 2007; Diaz et al., 2007; Kravtchenko et al., 1992).

The reaction products give information about the dominating type of degradation reactions. Acidic backbone hydrolysis produces only reducing sugars but ß-elimination additionally forms unsaturated uronides, which later on often cause non-enzymatic browning (Diaz et al., 2007).

Some important differences between dissolved pectins and pectin powders have to be considered for the investigation of thermal degradation processes:

- Pectin powders are complex systems with specific characteristics (Cuq et al., 2011) not only depending on the chemical composition but also on the material properties. The more or less compact structure of the pectin powder particles is crucial to the extent of adsorption and absorption of water for the degradation reactions (Einhorn-Stoll et al., 2015).

- Even if the surface of the particles is softening and partly starting to dissolve at high relative humidity (Matveev, Grinberg, \& Tolstoguzov, 2000; Basu, Shivhare, \& Muley, 2013), in contrast to pectin solutions the availability of water is limited in pectin powder.

- The limited amount of water in the climate chamber has an impact on the degradation reactions within the powder. Competitive effects between backbone hydrolysis, demethoxylation and hydrolytic cleavage of neutral sugar side chains occur. Since the two latter reactions are favoured in comparison to backbone hydrolysis (see above), the depolymerisation is the most restricted of these three reactions.

- The dissociation of carboxyl groups is lower in pectin powders than in solution and so is the $\mathrm{pH}$ influence on the degradation reactions. 


\section{Materials and methods}

\subsection{Materials}

A high-methoxylated commercial citrus pectin with DM $71 \%$ was kindly provided by Herbstreith und Fox (Neuenbürg, Germany) and is named as CP. The total lot was divided into portions, sealed under vacuum and stored at $-18{ }^{\circ} \mathrm{C}$ until use in order to minimize a possible influence of storage. All chemicals used in the study were of analytical grade.

\subsection{Methods}

\subsubsection{Pectin modification by different pre-treatments}

Various pectin types have been prepared by different procedures under laboratory conditions as described in Fig. 2. The optimum conditions for the acidic and alkaline demethoxylation have been tested before, in order to achieve comparable molecular parameters of the modified samples.

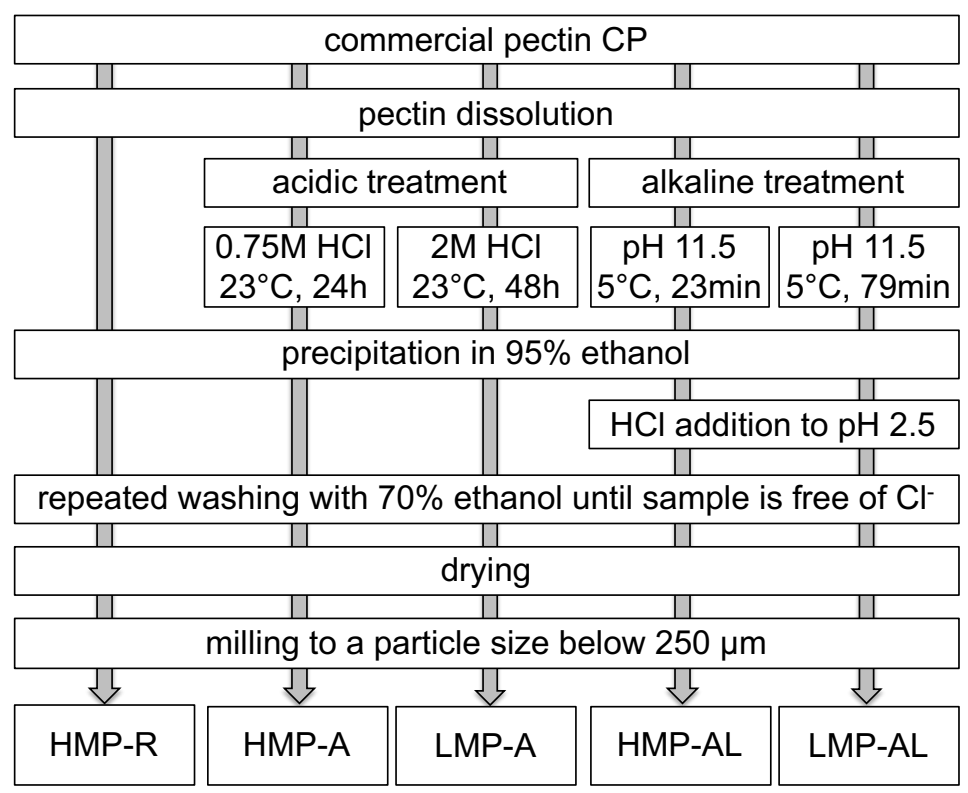

Fig. 2 Preparation of model pectins in laboratory scale. $C P=$ commercial pectin, HMP = high-methoxylated pectin, $L M P=$ low-methoxylated pectin, $-R=$ reference, $-A=$ acidic treated, $-A L=$ alkaline treated .

The acidic demethoxylation was performed in a batch method at room temperature using $\mathrm{HCl}$ as described before (Einhorn-Stoll, Glasenapp, \& Kunzek, 1996). For the alkaline demethoxylation, the pH-stat method using $\mathrm{NaOH}$ in a Titrando 902 with Dosino 800 (Metrohm GmbH, Filderstadt, Germany) was performed as described previously for enzymatic demethoxylation (Einhorn-Stoll et al., 2015b). The method was modified in $\mathrm{pH}(11.5)$ and temperature $\left(5^{\circ} \mathrm{C}\right)$ in order to minimize depolymerisation by ß-elimination. After demethoxylation and precipitation in ethanol, the $\mathrm{pH}$ was reduced to 2.5 with $10 \%$ hydrochloric acid and maintained for $30 \mathrm{~min}$ in order to remove sodium ions. Afterwards, the acidic ethanol was removed and the precipitate was washed several times with $70 \%$ ethanol until the washing liquid was free of chloride ions $\left(\mathrm{AgNO}_{3}\right.$-test). Two high-methoxylated pectins (DM about 60\%) and two low-metholxylated pectins (DM about 40\%) have been prepared. 
They have been named with respect to their DM as HMP (high-methoxylated pectin) and LMP (low-methoxylated pectin) and with respect to the demethoxylation method as $-\mathrm{A}$ (acidic) and $-\mathrm{AL}$ (alkaline).

The commercial pectin was additionally simply dissolved, precipitated and further treated in the same way like the demethoxylated samples. The resulting pectin was named as HMP-R (reference). The preparation of a reference was necessary, in order to compensate that the technological conditions, such as precipitation, grinding, drying and milling, in the laboratory scale differ strongly from those in industrial scale and result in different material properties such as particle size or bulk density.

\subsubsection{Thermal degradation - Thermolysis}

The thermal degradation was performed according to the procedure described before (Einhorn-Stoll \& Kunzek, 2009). The samples were spread in Petri dishes (0.5 - 1cm layer height) and a distance holder kept the lid slightly open. They were stored in a climate chamber KBF 115 with a controlled humidity system (Binder, Tuttlingen, Germany) at $60{ }^{\circ} \mathrm{C}$ and $80 \%$ relative humidity for four weeks. Samples for the examination of the degradation kinetic were taken after 7, 14 and 21 days. After incubation, the pectins were dried at room temperature in a desiccator in order to remove absorbed water and stored at $-10{ }^{\circ} \mathrm{C}$ before analysis.

\subsubsection{Pectin characterisation}

The galacturonan content (GC) and DM were determined by photometric methods. The mhydroxydiphenyl method (Blumenkrantz, , Asboe-Hansen, 1973) was applied for the determination of the free uronic acids (GC) and the chromotropic acid method (Bäuerle, Otterbach, Gierschner \& Baumann, 1977) for the DM. All determinations were performed in duplicate.

The intrinsic viscosity ([ๆ]) was analysed using a rolling ball micro viscosimeter LOVIS 2000M (Anton Paar GmbH, Ostfildern-Scharnhausen, Germany) as described by Mende et al., (2013). Determinations were performed in duplicate with 16 single values per determination. Standard deviation was calculated by Excel.

The molecular weight distribution has been determined by gel permeation chromatography (GPC) using the parameters and instruments as described recently (Wegener, Kaufmann, \& Kroh, 2017). The calibration function was as follows: elution time $15 \mathrm{~min} \approx 380 \mathrm{kD}, 17 \mathrm{~min} \approx 100 \mathrm{kD}, 19 \mathrm{~min} \approx$ $12 \mathrm{kD}$ and $21 \mathrm{~min} \approx 0.3 \mathrm{kD}$.

For colour determination, the dry samples before and after incubation were examined with a Chromameter CR 300 (Minolta, Japan) using the CIELAB system (10 measurements per sample). The positive a- and b-values (red and yellow) are good indicators for the increasing browning reaction of the pectins. Standard deviation was calculated by Excel. 
The protein content was examined in duplicate using a Dumatherm N64+ (Gerhardt, Königswinter, Germany).

The content of sodium ions was examined from the ash by flame photometry using a Perkin Elmer Aanalyst 800 (USA) and an acetylene/air gas mixture. All determinations were performed in duplicate.

Neutral sugars (NS) have been analysed in duplicate by HPAEC-PAD (pump: Shimadzu LC-20AD SP; columns: CarboPac ${ }^{\text {TM }}$ Bio LC ${ }^{\mathrm{TM}} 4 \times 50$ mm Guard, CarboPac ${ }^{\mathrm{TM}}$ PA10 4-mm, CarboPac ${ }^{\mathrm{TM}}$ PA1 4×250 mm; detector, Dionex PAD-2) after a pre-treatment with Rapidase Smart (DSM Food Specialties), Ultrazyme and TFA, adapted from Garna, Mabon, Nott, Wathelet, \& Paquot (2006).

The bulk density was determined in duplicate by weighing a bulk of pectin in a $10 \mathrm{ml}$ graduated cylinder.

The $\mathrm{pH}$ of the dissolved samples has been determined in duplicate in a $0.1 \mathrm{wt}$ \% solution after stirring at room temperature for $3 \mathrm{~h}$ using a pH-meter WTW 539 (WTW, Weilheim, Germany).

\subsubsection{Thermal Analysis}

The simultaneous thermal analysis (combination of differential scanning calorimetry (DSC) and thermogravimetry (TG) was carried out in duplicate using a STA 449 F3 Jupiter (Netzsch, Selb, Germany) under the following conditions: linear heating rate $10 \mathrm{~K} / \mathrm{min}$ from 20 to $450{ }^{\circ} \mathrm{C}$, dynamic inert helium atmosphere $(70 \mathrm{~mL} / \mathrm{min}), 85 \mu \mathrm{L}$ Pt open crucible, empty crucible as reference, sample weight approximately $20 \mathrm{mg}$. All runs were performed in duplicate. The instrument was calibrated by a standard procedure and the extrapolated onset $\left(T_{o n}\right)$ and peak $\left(T_{p}\right)$ temperature of the DTG signal were calculated using the Netzsch Proteus software as described previously (Einhorn-Stoll, Kunzek, \& Dongowski, 2007). 


\section{Results}

The parameters of the investigated pectins are shown in Table 1 and the main properties of the degraded pectins in Table 2 and 3. Since the properties of the initial samples (= pectins before degradation) differed considerably, the alterations of colour, DM and [ $\eta]$ during degradation (Fig. 3-5) are shown as relative decrease or increase. The parameters of the initial samples are defined as $100 \%$. The sample mass increase by water uptake was found to be 5 to $8 \%$ during four weeks of storage (data not shown).

Table 1 Parameters of the examined pectins. $C P=$ commercial pectin, HMP = high-methoxylated pectin, LMP = lowmethoxylated pectin, $-R=$ reference, $-A=$ acidic- treated, $-A L=$ alkaline-treated. $G C=$ galacturonan content, $D M$ = degree of methoxylation, $[\eta]=$ intrinsic viscosity, $a$ - and $b$-value $=$ colour values, $N S=$ neutral sugars content. \pm = ranges of single measurements from medium values. The ranges / standard deviation of the parameters DM, [ $\eta$ ] and colour are presented in Table 2.

\begin{tabular}{|c|c|c|c|c|c|c|}
\hline & $\mathrm{CP}$ & HMP-R & HMP-A & LMP-A & HMP-AL & LMP-AL \\
\hline GC [\%] & $75.0 \pm 0.1$ & $73.6 \pm 1.6$ & $83.7 \pm 0.5$ & $86.1 \pm 1.4$ & $80.9 \pm 1.5$ & $83.6 \pm 0.8$ \\
\hline DM [\%] & 71.4 & 71.5 & 59.4 & 37.2 & 57.9 & 39.6 \\
\hline$[\eta]\left[\mathrm{cm}^{3} / \mathrm{g}\right]$ & 640 & 627 & 619 & 603 & 528 & 425 \\
\hline a-value & 1.68 & 1.08 & 1.47 & 1.81 & 0.78 & 1.03 \\
\hline b-value & 17.31 & 12.40 & 14.01 & 15.08 & 10.47 & 11.34 \\
\hline Protein [\%] & $1.26 \pm 0.03$ & $1.23 \pm 0.01$ & $1.09 \pm 0.01$ & $0.99 \pm 0.01$ & $0.94 \pm 0.01$ & $0.98 \pm 0.01$ \\
\hline Sodium ions [\%] & $0.46 \pm 0.02$ & $0.46 \pm 0.02$ & $<0.01$ & $<0.01$ & $0.28 \pm 0.01$ & $0.52 \pm 0.04$ \\
\hline Neutral sugars [\%] & $8.9 \pm 0.4$ & $8.8 \pm 0.5$ & $6.8 \pm 0.2$ & $5.1 \pm 0.5$ & $8.2 \pm 0.25$ & $8.8 \pm 0.1$ \\
\hline Bulk density $\left[\mathrm{g} / \mathrm{cm}^{3}\right]$ & 0.525 & 0.289 & 0.438 & 0.575 & 0.240 & 0.224 \\
\hline pH in solution & 3.73 & 3.70 & 3.25 & 3.13 & 3.41 & 3.74 \\
\hline
\end{tabular}

The pectin parameters and their alterations, resulting from thermolysis, are as follows:

\subsection{Colour and browning}

The initial pectins had different colours (Table 1). The a-values (red) varied from 0.78 to 1.81 and the b-values (yellow) from 10.47 to 17.31. High values were found for the commercial pectin (CP) and the acidic treated $(A)$ samples, whereas the values for the reference $(R)$ pectin and the alkaline treated $(A L)$ samples have been much lower. The variations result mainly from different material properties, especially bulk density. This parameter was differing, too, between 0.224 for LMP-AL and $0.575 \mathrm{~g} / \mathrm{cm}^{3}$ for LMP-A (Table 1). The reference pectin and, even more pronounced, the alkaline treated samples had a structure that is often described as "fluffy".

Browning of the degraded pectin powders as increase of a- and b-values is the first visible indicator of pectin degradation by demethoxylation and depolymerisation as described before (Einhorn-Stoll \& Kunzek, 2009). All samples showed this increase with only small differences in intensity between the individual pectin types (Table 2, Fig. 3). 
Table 2 Alteration of pectin properties during thermolysis after $7 / 14 / 21 / 28$ days in the climate chamber. $C P=$ commercial pectin, HMP = high-methoxylated pectin, $L M P=$ low-methoxylated pectin, $-R=$ reference, $-A=$ acidic treated, $-A L=$ alkaline treated. $D M=$ degree of methoxylation, $D M \pm=$ range of single $D M$ measurements from average, $[\eta]=$ intrinsic viscosity, $S D[\eta]=$ standard deviation of $[\eta]$, a- and b-values $=$ colour values.

\begin{tabular}{|c|c|c|c|c|c|c|c|c|}
\hline $\begin{array}{l}\text { Sample/ } \\
\text { Degradation } \\
\text { time }\end{array}$ & $\begin{array}{l}\text { DM } \\
{[\%]}\end{array}$ & $\begin{array}{c}\text { DM } \\
\pm\end{array}$ & $\begin{array}{c}{[\eta]} \\
{\left[\mathrm{cm}^{3} / \mathrm{g}\right]}\end{array}$ & $\begin{array}{l}\text { SD } \\
{[\eta]}\end{array}$ & $\mathbf{a}$ & $\begin{array}{c}\text { SD } \\
a\end{array}$ & b & $\begin{array}{c}S D \\
b\end{array}$ \\
\hline CP & 71.4 & 0.6 & 640 & 10 & 1.68 & 0.057 & 17.31 & 0.28 \\
\hline $7 d$ & 60.2 & 0.2 & 503 & 5 & 3.73 & 0.09 & 19.93 & 0.29 \\
\hline $14 \mathrm{~d}$ & 55.0 & 0.9 & 383 & 6 & 4.39 & 0.02 & 21.97 & 0.14 \\
\hline $21 d$ & 50.1 & 0.4 & 294 & 5 & 5.76 & 0.06 & 24.04 & 0.21 \\
\hline $28 d$ & 44.4 & 0.4 & 254 & 9 & 6.87 & 0.05 & 24.89 & 0.14 \\
\hline HMP-R & 71.5 & 0.2 & 627 & 10 & 1.082 & 0.043 & 12.40 & 0.04 \\
\hline $7 d$ & 61.9 & 0.3 & 408 & 9 & 1.878 & 0.02 & 14.68 & 0.05 \\
\hline $14 \mathrm{~d}$ & 55.4 & 0.9 & 280 & 9 & 2.654 & 0.03 & 16.58 & 0.19 \\
\hline $21 d$ & 42.7 & 0.5 & 225 & 7 & 3.557 & 0.05 & 18.47 & 0.10 \\
\hline $28 d$ & 37.0 & 0.2 & 155 & 5 & 4.578 & 0.03 & 20.32 & 0.04 \\
\hline HMP-A & 59.4 & 1.4 & 619 & 12 & 1.47 & 0.043 & 14.01 & 0.13 \\
\hline $7 d$ & 35.6 & 0.6 & 214 & 6 & 2.48 & 0.02 & 16.32 & 0.04 \\
\hline $14 d$ & 17.4 & 0.1 & 132 & 7 & 3.15 & 0.03 & 18.24 & 0.16 \\
\hline $21 d$ & 9.8 & 0.2 & 108 & 7 & 4.01 & 0.05 & 20.75 & 0.14 \\
\hline $28 d$ & 7.6 & 0.0 & 93 & 6 & 5.12 & 0.03 & 23.37 & 0.08 \\
\hline LMP-A & 37.2 & 1.0 & 603 & 12 & 1.81 & 0.099 & 15.08 & 0.49 \\
\hline $7 d$ & 16.5 & 0.3 & 201 & 5 & 3.07 & 0.04 & 17.83 & 0.10 \\
\hline $14 \mathrm{~d}$ & 9.1 & 0.3 & 115 & 6 & 3.84 & 0.05 & 19.92 & 0.15 \\
\hline $21 d$ & 4.4 & 0.0 & 105 & 3 & 4.95 & 0.07 & 22.72 & 0.30 \\
\hline $28 d$ & 3.7 & 0.1 & 87 & 6 & 5.95 & 0.10 & 24.76 & 0.29 \\
\hline HMP-AL & 57.9 & 0.6 & 528 & 7 & 0.78 & 0.03 & 10.47 & 0.05 \\
\hline $7 d$ & 43.06 & 0.4 & 383 & 7 & 1.61 & 0.01 & 13.39 & 0.08 \\
\hline $14 \mathrm{~d}$ & 26.7 & 0.6 & 296 & 6 & 2.06 & 0.02 & 15.28 & 0.18 \\
\hline $21 d$ & 18.86 & 0.4 & 238 & 7 & 2.52 & 0.04 & 16.71 & 0.11 \\
\hline $28 d$ & 11.49 & 0.0 & 200 & 6 & 3.42 & 0.07 & 19.07 & 0.13 \\
\hline LMP-AL & 38.41 & 0.7 & 425 & 6 & 1.03 & 0.02 & 11.34 & 0.06 \\
\hline $7 d$ & 28.84 & 0.1 & 353 & 7 & 1.68 & 0.02 & 13.69 & 0.09 \\
\hline $14 \mathrm{~d}$ & 18.87 & 0.0 & 287 & 7 & 2.38 & 0.05 & 16.01 & 0.30 \\
\hline $21 d$ & 12.9 & 0.1 & 263 & 6 & 2.91 & 0.03 & 17.52 & 0.05 \\
\hline $28 d$ & 9.0 & 0.0 & 225 & 5 & 3.92 & 0.09 & 19.97 & 0.34 \\
\hline
\end{tabular}
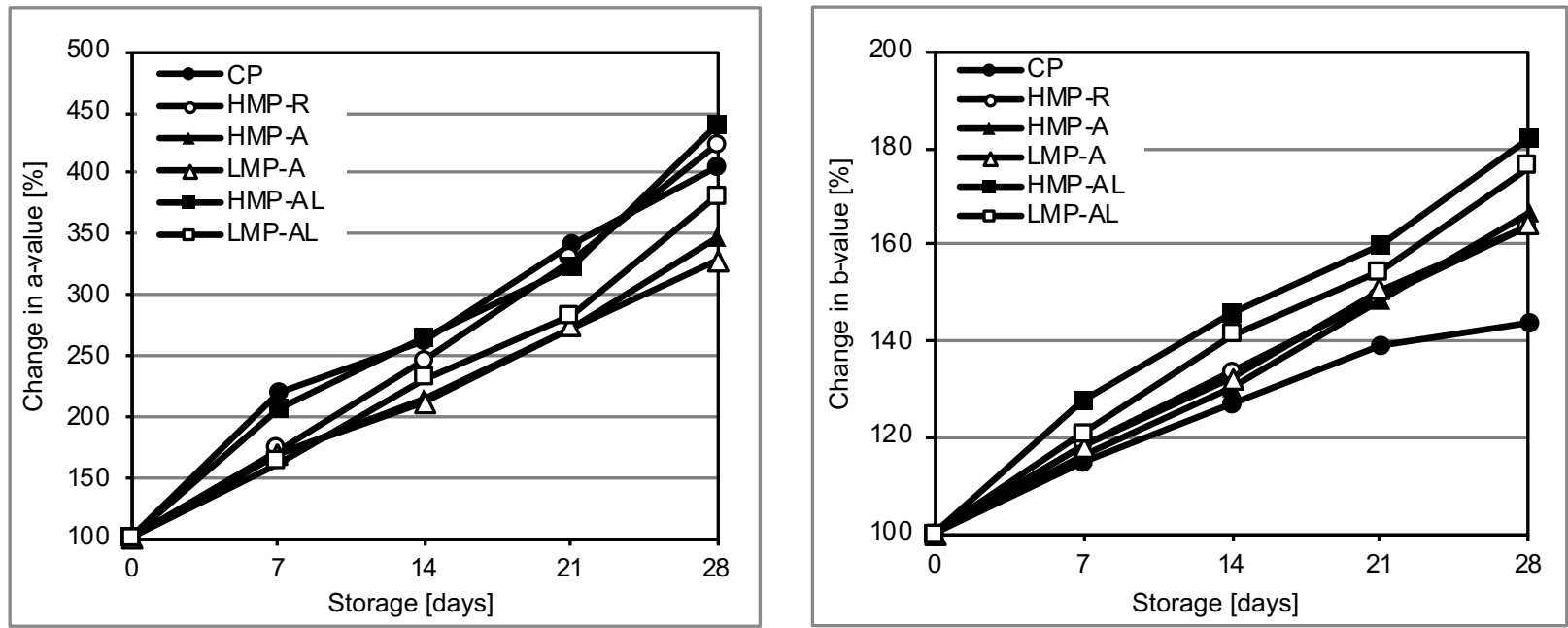

Fig. 3 Relative increase of red (a-value) and yellow (b-value) colour during thermolysis. 


\subsection{Degree of methoxylation and demethoxylation reactions}

The preparation of the reference pectin did not alter the DM. The DM of the demethoxylated HMP and LMP, respectively, were comparable (Table 1).

The decrease of DM was the lowest for CP and HMP-R (from about $70 \%$ to about $40 \%$, Table 2, Fig. 4), even though they had the highest initial DM. The alkaline treated samples were demethoxylated stronger than CP and HMP-R with up to about $20 \%$ of the initial values, and the reaction was nearly independent on their initial DM. The demethoxylation of the acidic treated samples was the most intensive with up to about $10 \%$ of the initial values. Their reaction rate was highest in the first two weeks and there was a difference in dependence on their initial DM. For the demethoxylation intensity after four weeks of thermolysis the ranking was:

CP $<$ HMP-R $<$ LMP-AL $<$ HMP-AL $<$ HMP-A $<$ LMP-A

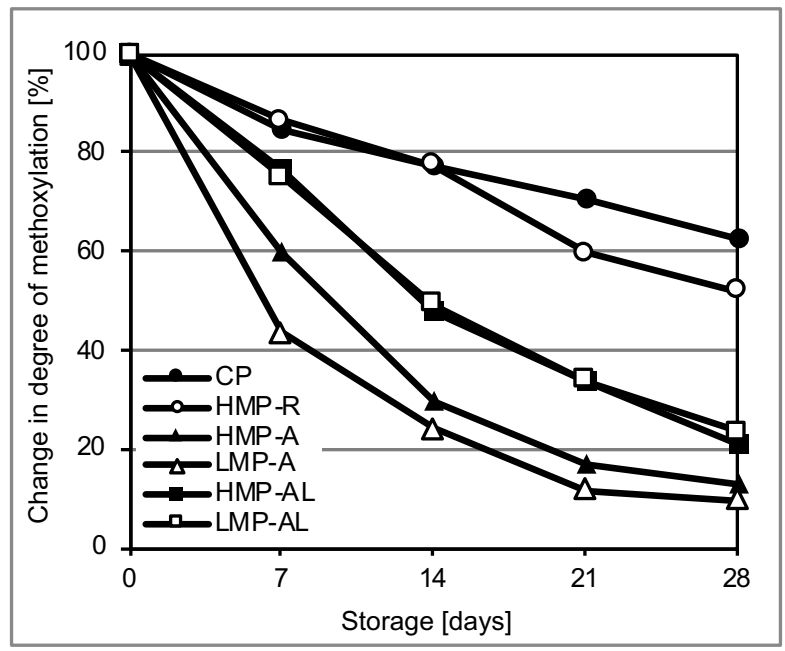

Fig. 4 Relative decrease of the degree of methoxylation (DM) during thermolysis.

\subsection{Intrinsic viscosity and depolymerisation}

The intrinsic viscosity of the initial pectin samples was similar for CP, HMP-R and the acidic treated samples but slightly reduced for the alkaline treated (Table 1).

The kinetic of depolymerisation of some of the pectins, shown as decrease of [ $\eta$, differed from their demethoxylation kinetic (Table 2, Fig. 5), and both reactions had no simultaneous course of intensity. The depolymerisation of the reference pectin was much more intensive than that of the commercial pectin (from about 630 to 150 and $250 \mathrm{~cm}^{3} / \mathrm{g}$, respectively), and the alkaline treated samples had a low decrease from 530 and 430, respectively, to about $200 \mathrm{~cm}^{3} / \mathrm{g}$. Once more, the reaction rate of the acidic treated pectins was the highest, $[\eta]$ decreased from about 610 to below $100 \mathrm{~cm}^{3} / \mathrm{g}$. After four weeks of thermolysis, the results of [ $\left.\eta\right]$-decrease were in the following ranking: LMP-AL $<<$ CP $<$ HMP-AL $<$ HMP-R $<$ HMP-A $=$ LMP-AC 


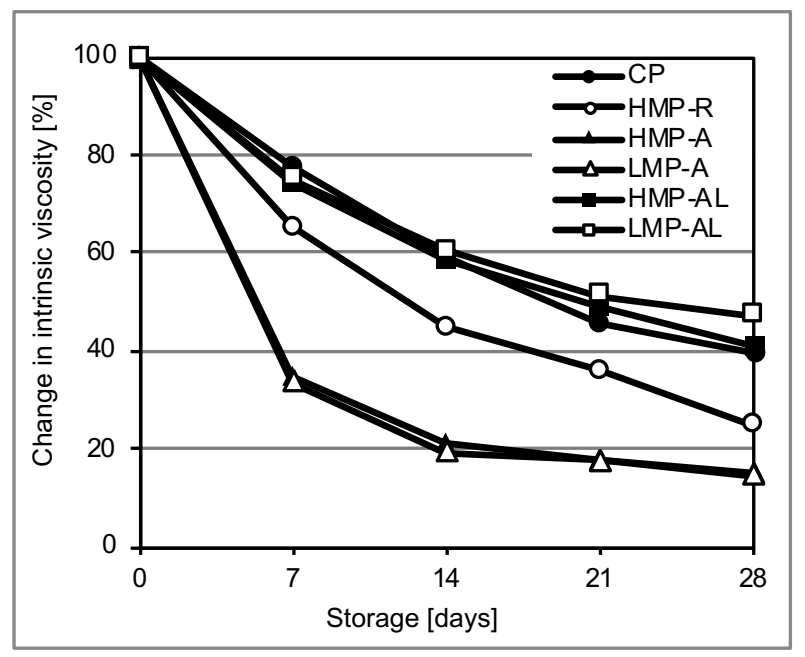

Fig. 5 Relative decrease of the intrinsic viscosity ([n]) during thermolysis.

The results of GPC (Fig. 6a-c) before degradation and after two and four weeks of thermolysis support the results of the $[\eta]$. The initial demethoxylated samples LMP-A (Fig. 6b) and LMP-AL (Fig. 6c) showed a broader molecular weight (MW) distribution above $380 \mathrm{kDa}$ (elution time 10 to $15 \mathrm{~min}$ ) than CP (Fig. 6a). Moreover, they had an additional small peak with a MW about $12 \mathrm{kDa}$ (elution time $19 \mathrm{~min}$ ), resulting from depolymerisation as a side reaction of demethoxylation. After four weeks of storage, the CP main peak was decreased and a very small new peak with a MW about $0.3 \mathrm{kDa}$ (elution time $21 \mathrm{~min}$ ) has been formed. The LMP-A showed a very strong reduction of the two initial peaks, a newly formed peak at $0.3 \mathrm{kDa}$ already after two weeks of storage and a further peak shift / increase after four weeks. In agreement with its lower initial [ $\eta$, the LMP-AL had the smallest initial main peak. This peak, as well as the second one at $12 \mathrm{kDa}$, was reduced to a certain extent after four weeks but not as far as the peaks of LMP-A. The new peak at $0.3 \mathrm{kDa}$ was found here, too.
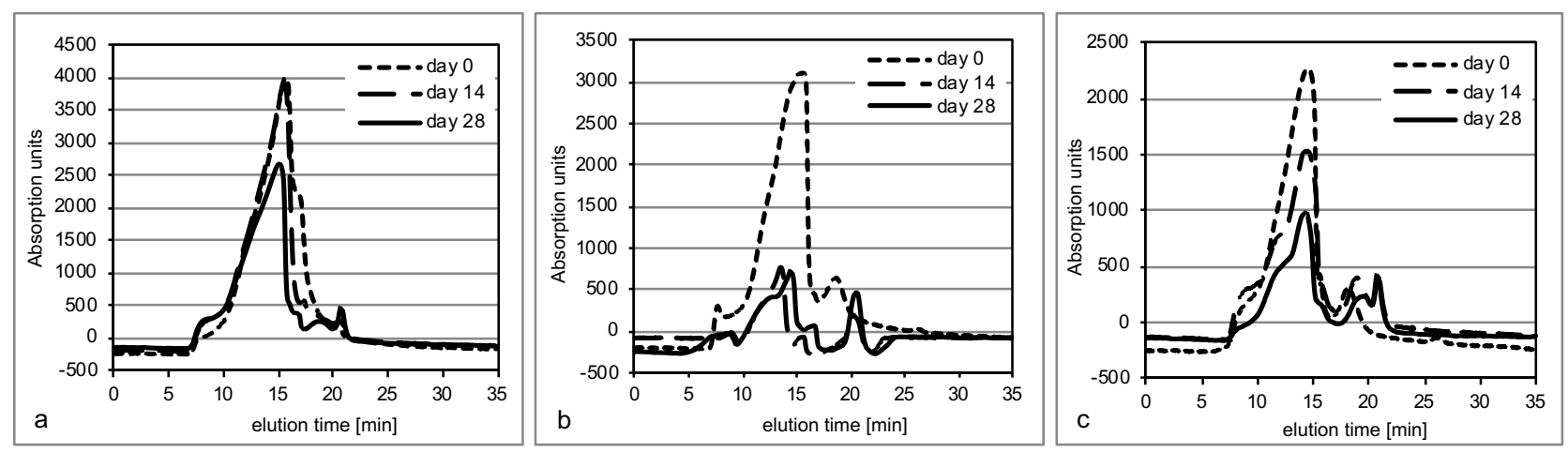

Fig. 6 GPC images of the initial and degraded pectins after 14 days and 28 days of thermolysis. a) $C P, b) L M P-A, c)$ $L M P-A L$ 


\subsection{Sodium ion content}

The content of sodium ions of the pectins varied considerably and was found between $<0.01 \%$ in acidic treated and 0.52 for the LMP-AL (Table 1).

\subsection{Neutral sugar content}

The NS contents of the initial samples varied (Table 1). They were similar and high at about $8.8 \%$ for the original, reference and alkaline treated samples but have been considerably reduced to 5.1 and $6.8 \%$, respectively, for the acidic treated.

In the supernatants after precipitation of HMP-R and of acidic treated samples, neutral sugars have been detected (Fig. 7).
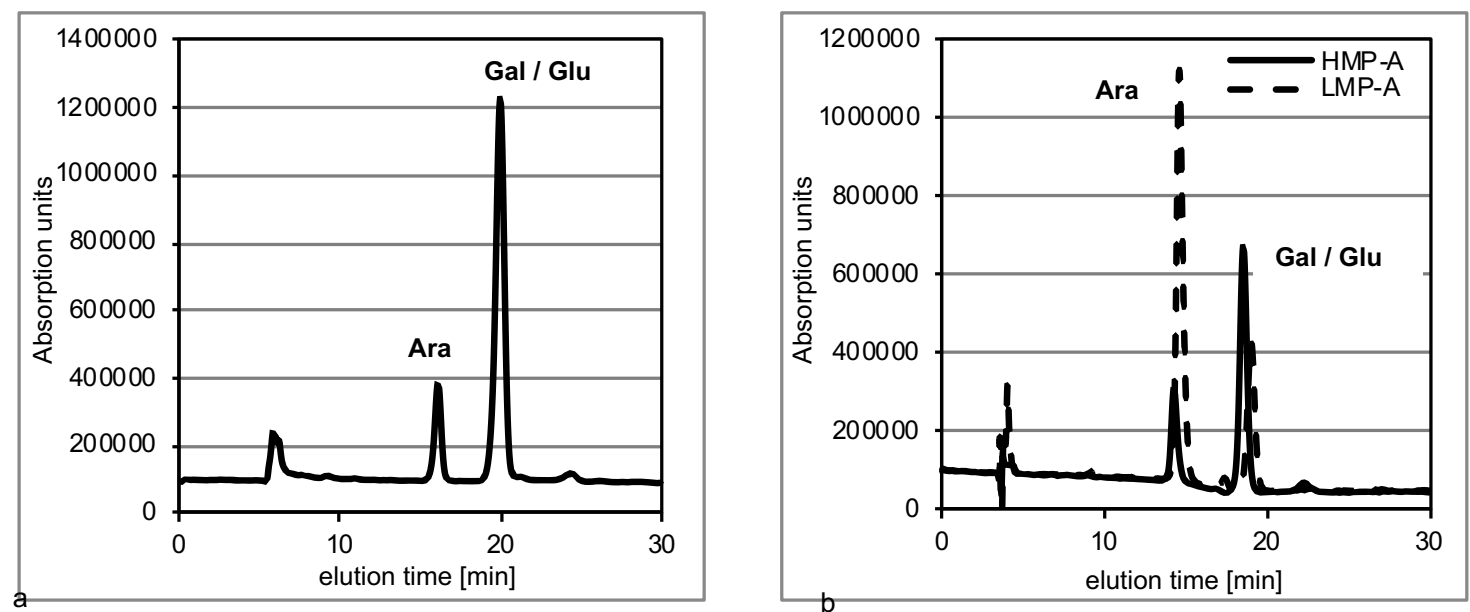

Fig. 7 Neutral sugars in the supernatant after precipitation of a) the reference sample (HMP-R) and $b)$ acidic treated samples (HMP-A and LMP-A). Gal = Galactose, Glu = Glucose, Ara = Arabinose

The alterations of the NS contents after thermolysis varied (Fig. 8). Whilst the values of CP showed no clear tendency, the contents of neutral sugars of HMP-R and the alkaline treated samples decreased (comparison of 0 and $28 \mathrm{~d}$ ) and the values of the acidic treated samples showed an increase after 14 days of storage.

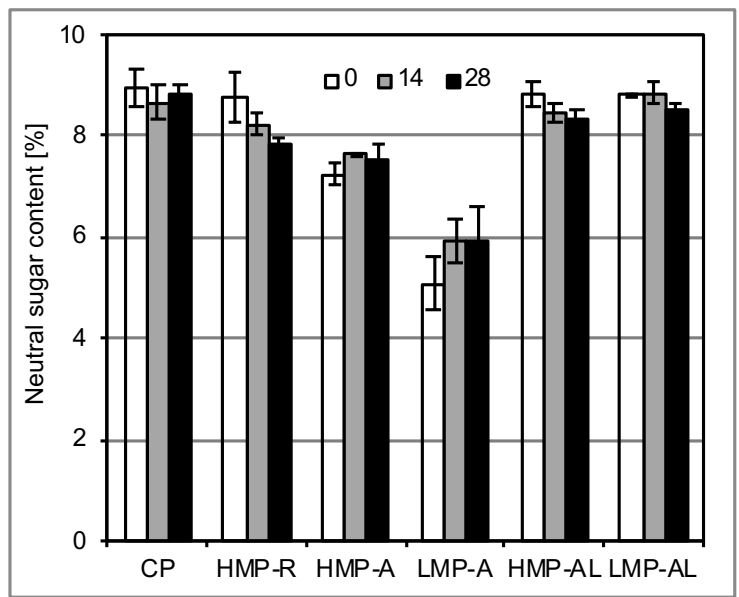

Fig. 8 Alteration of neutral sugar content of the initial and degraded pectins after 0, 14 and 28 days of thermolysis. 


\section{6. $p H$ of pectin solutions}

The $\mathrm{pH}$-values of the pectins (Table 1) ranged from 3.1 to 3.7 , which is close to $\mathrm{pH} 3.5$, the typical $\mathrm{pK}_{\mathrm{a}}$ of pectins. The $\mathrm{pH}$-values of the acidic treated samples were below $\mathrm{pK}_{\mathrm{a}}$, those of all other samples were above.

\subsection{Results of thermal analysis}

Thermal analysis results show the intensity of pectin degradation. It is known from previous works, that demethoxylation (Einhorn-Stoll et al., 2007) especially in combination with depolymerisation after thermolysis (Einhorn-Stoll \& Kunzek, 2009) causes a shift of the DSC and DTG signals to the left side. That means a start of mass reduction at lower temperature and an earlier pyrolysis in an oxygen-free atmosphere. These effects were found also in this work. The peak shift in the DTG signals was much more distinct in case of the acidic treated pectins than for the alkaline treated. In comparison of all samples, using the extrapolated onset temperature $T_{\text {on }}$ of the DTG peaks (Table 3 , Fig. 9), the intensity of the DTG peak shift showed the highest decrease for the acidic treated samples (minus $7 \mathrm{~K}$ ) and the smallest alterations for the unmodified $\mathrm{CP}$ (minus $2 \mathrm{~K}$ ). There was also an influence of the DM of the demethoxylated initial samples, the two modified HMP showed a stronger peak shift than the two corresponding LMP. The same tendency was found for the peak temperatures $T_{p}$ of the DTG-signals (Table 3 ). An additional alteration was detected in the DSC signal of the acidic treated samples (Fig. 10). A characteristic endothermic peak at the begin of the pyrolysis, which was not detected in the other pectin samples, decreased with increasing degradation of the pectin. This was indicating a decreasing energy barrier at the start of the pyrolysis process.

Table 3 Alterations of the extrapolated onset temperature $T_{\text {on }}$ and the peak temperature $T_{p}$ of the DTG signals during thermolysis (range of temperatures of single parallel measurements was 0.1 to $0.3 \mathrm{~K}$ ).

\begin{tabular}{ccccccccc}
\hline $\begin{array}{l}\text { Sample/ } \\
\begin{array}{l}\text { Degradation } \\
\text { time }\end{array}\end{array}$ & $\begin{array}{c}\mathbf{T}_{\text {on DTG }} \\
{\left[{ }^{\circ} \mathbf{C}\right]}\end{array}$ & $\begin{array}{l}\mathbf{T}_{\mathbf{p} \text { DTG }} \\
{\left[{ }^{\circ} \mathbf{C}\right]}\end{array}$ & $\begin{array}{l}\text { Sample/ } \\
\text { Degradation } \\
\text { time }\end{array}$ & $\begin{array}{c}\mathbf{T}_{\text {on DTG }} \\
{\left[{ }^{\circ} \mathbf{C}\right]}\end{array}$ & $\begin{array}{l}\mathbf{T}_{\mathbf{p} \text { DTG }} \\
{\left[{ }^{\circ} \mathbf{C}\right]}\end{array}$ & $\begin{array}{l}\text { Sample/ } \\
\text { Degradation } \\
\text { time }\end{array}$ & $\begin{array}{c}\mathbf{T}_{\text {on DTG }} \\
{\left[{ }^{\circ} \mathbf{C}\right]}\end{array}$ & $\begin{array}{c}\mathbf{T}_{\mathbf{p} \text { DTG }} \\
{\left[{ }^{\circ} \mathbf{C}\right]}\end{array}$ \\
\hline CP & $\mathbf{2 2 7 . 2}$ & $\mathbf{2 4 1 . 7}$ & HMP-A & $\mathbf{2 4 3 . 8}$ & $\mathbf{2 6 3 . 1}$ & HMP-AL & $\mathbf{2 2 7 . 2}$ & $\mathbf{2 5 0 . 3}$ \\
$7 \mathrm{~d}$ & 226.4 & 225.3 & $7 \mathrm{~d}$ & 229.8 & 253.1 & $7 \mathrm{~d}$ & 226.7 & 247.8 \\
$14 \mathrm{~d}$ & 225.3 & 241.6 & $14 \mathrm{~d}$ & 224.2 & 249.7 & $14 \mathrm{~d}$ & 223.0 & 245.8 \\
$21 \mathrm{~d}$ & 224.9 & 240.9 & $21 \mathrm{~d}$ & 222.5 & 248.8 & $21 \mathrm{~d}$ & 218.9 & 244.5 \\
$28 \mathrm{~d}$ & 223.7 & 239.9 & $28 \mathrm{~d}$ & 221.0 & 247.8 & $28 \mathrm{~d}$ & 215.7 & 243.6 \\
HMP-R & $\mathbf{2 2 6 . 7}$ & $\mathbf{2 4 3 . 0}$ & LMP-A & $\mathbf{2 3 3 . 5}$ & $\mathbf{2 5 3 . 5}$ & LMP-AL & $\mathbf{2 2 3 . 1}$ & $\mathbf{2 4 2 . 5}$ \\
$7 \mathrm{~d}$ & 226.7 & 242.8 & $7 \mathrm{~d}$ & 224.4 & 248.9 & $7 \mathrm{~d}$ & 221.2 & 241.4 \\
$14 \mathrm{~d}$ & 225.8 & 242.5 & $14 \mathrm{~d}$ & 217.0 & 247.7 & $14 \mathrm{~d}$ & 219.1 & 240.4 \\
$21 \mathrm{~d}$ & 224.4 & 242.0 & $21 \mathrm{~d}$ & 216.2 & 246.9 & $21 \mathrm{~d}$ & 218.0 & 240.0 \\
$28 \mathrm{~d}$ & 223.2 & 240.7 & $28 \mathrm{~d}$ & 216.0 & 246.5 & $28 \mathrm{~d}$ & 217.6 & 239.9 \\
\hline
\end{tabular}




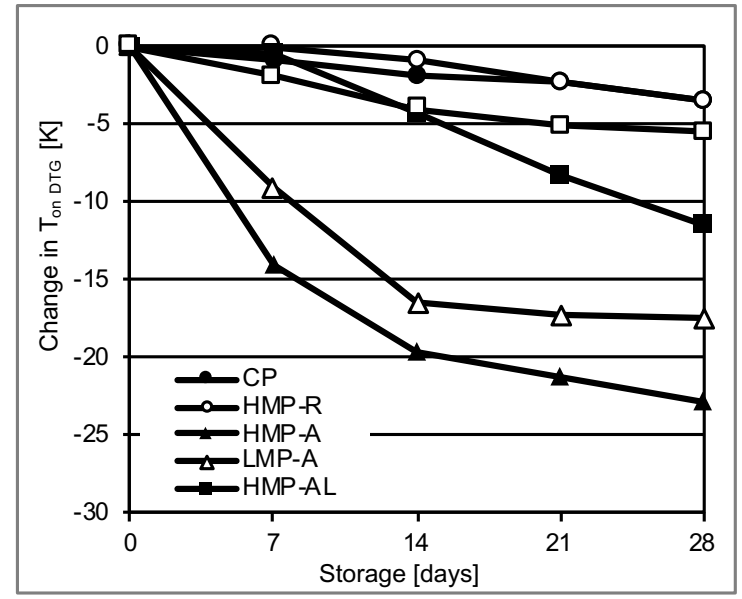

Fig. 9 Decrease of the extrapolated onset-Temperature of the DGT-peak during thermolysis.

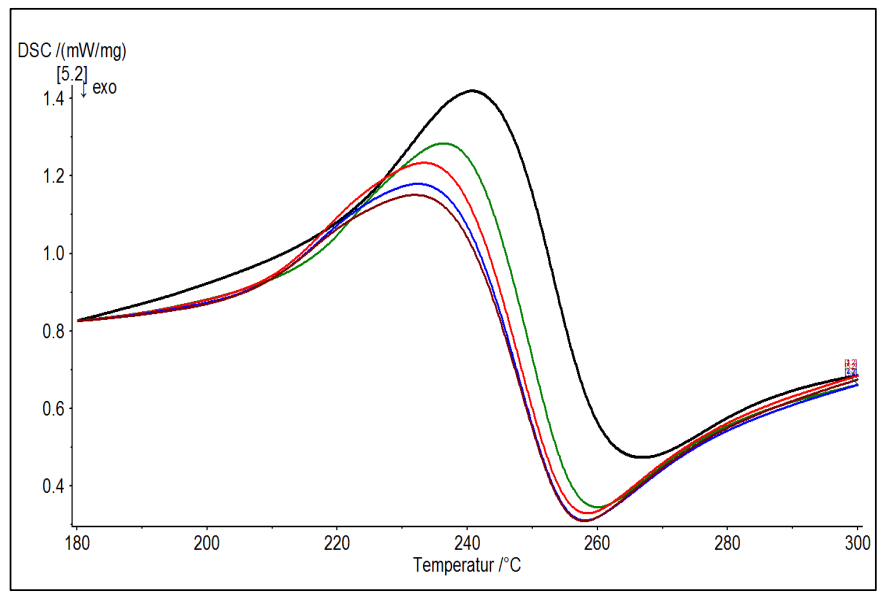

Fig. 10 Shift of DSC-signals of the thermal analysis and reduction of the endothermic peak at the start of pyrolysis of initial and degraded LMP-A. 


\section{Discussion}

\subsection{General remarks}

The type of pre-treatment had an impact not only on the molecular parameters of the modified pectins but also on their material properties, as shown by the different results for the bulk density. This was crucial for the water intrusion into the pectin powder particles and the water availability for degradation reactions. The lower the bulk density, the fluffier were the samples and the easier available was the water for the degradation reactions.

The NS D-glucose, D-galactose and arabinose, which were found in the supernatants after precipitation of HMP-R as well as of the acidic treated samples, resulted from different sources. The re-precipitation removed only unbound NS (mostly glucose and galactose) that were sticking as residuals from the pectin preparation process to or mixed with pectin powder particles. In contrast, acidic pre-treatments additionally cleaved some of the neutral sugar side chains by acidic hydrolysis which were removed by precipitation. Therefore, the detected amounts of arabinose, which is bound in the side chains, where higher after acidic modification than after re-precipitation.

All degradation reactions in pectin solution more or less depend on the $\mathrm{pH}$. Since this influence on degradation in pectin powder was limited and the differences in $\mathrm{pH}$ between the single samples were so small, these differences will not be broadly discussed in this work. It should be considered, however, that the $\mathrm{pH}$-values of the completely dissolved samples (3.1 - 3.7) were generally more favourable for the hydrolytic reactions than for the ß-elimination, despite ß-elimination was detected already at $\mathrm{pH}$ around 3.5. A certain acidic backbone hydrolysis might be expected in LMP be enhanced by the parallel demethoxylation. In contrast, for the HMP (in particular for CP and HMP-R) ß-elimination should be the dominating reaction.

The focus of the discussion will be on the effect of the modification by different pre-treatments on type and extent of the various and partly competing degradation reactions and their kinetic during the storage time of four weeks. Most of the considered classical reactions, demethoxylation, depolymerisation by backbone hydrolysis and hydrolytic cleavage of neutral sugar side chains, required water and competed for the limited moisture in the system. Backbone hydrolysis was known to be the least probable of these three reactions, and it was additionally restricted by the protecting influence of free carboxyl as well as ester groups at C-5. For these reasons, this reaction will not be discussed in detail for most of the investigated pectins. The well-known depolymerisation by ß-eliminations needs no water and was more probable for depolymerisation of the most tested pectins than backbone hydrolysis. The hypothesis of an additional depolymerisation reaction by an eliminative decarboxylation that requires no water, too, (Einhorn-Stoll \& Kunzek, 2009) was considered. 


\subsection{Original pectin}

The degradation of CP was the least of all tested samples with respect to demethoxylation and depolymerisation, and it also caused the smallest shift of the DTG-peak. This pectin united many factors that had a limiting impact on any degradation. The compact particle structure, represented by a high bulk density, restricted water intrusion and, as a consequence, all reactions which would require water. It contained a high share of NS, and the cleavage of the NS side chains competed for water with demethoxylation. CP had, however, a high content of sodium ions bound to the free carboxyl groups (-COONa), which might have supported the ß-elimination as described by Sajjaanantakul et al. (1993). Unsaturated uronides were formed by ß-elimination and caused browning as indicated by increasing a- and b-values. Unbound NS might have contributed to the special browning of CP with high increase in a-value and low increase in b-value, either alone (Sugisawa \& Sudo, 1969) or in combination with protein in a Maillard reaction (for instance Tressl, Wondrak, Garbe, \& Rewicki, 1998).

\subsection{Re-precipitated reference pectin}

Demethoxylation was slightly higher and depolymerisation was much more pronounced in this pectin in comparison to $\mathrm{CP}$, though most molecular parameters of the two samples were similar. However, the less compact powder particles (reduced bulk density) of HMP-R allowed an easier water intrusion (Einhorn-Stoll, Hatakeyama, \& Hatakeyama, 2012), which favoured the waterconsuming reactions demethoxylation, NS cleavage and, to al low extent, backbone hydrolysis. Depolymerisation was assumed to be caused mainly by ß-elimination, which also resulted in a certain amount of browning. Some of the side-chain NS have been cleaved from the backbone by thermolysis, and from their decreasing content during storage it is assumed that they were also partly degraded and formed additional coloured reaction products.

\subsection{Alkaline treated pectins}

The initial molecular weights of the alkaline treated pectins were lower than those of all other tested samples. Though the temperature was low and the $\mathrm{pH}$ was high during alkaline demethoxylation, a certain depolymerisation by ß-elimination already during this pre-treatment could not be prevented. The sodium ion content of the HMP-AL was lower than those of CP and HMP-R since the original ions and some of those added by $\mathrm{NaOH}$ during demethoxylation by $\mathrm{pH}$-stat method have been partly removed by the acidic treatment after alkaline demethoxylation. In contrast, the LMP-AL had the highest sodium content of all samples. This was caused by the high amount of ions which were added and irreversibly bound to the newly-formed free carboxyl groups during demethoxylation. The sodium ions have contributed to the low bulk density of the alkaline treated pectins (lowest of all samples), as was reported before (Einhorn-Stoll et al, 2012), and to an easier water intrusion during 
thermolysis. Demethoxylation, that requires water, was much more pronounced in alkaline treated pectins than in HMP-R and CP because of the more favourable material properties.

In contrast, out of all tested pectins, depolymerisation was lowest in HMP-AL and LMP-AL. Backbone hydrolysis, which might have been enhanced by more available water and the increasing number of free carboxyl groups after stronger demethoxylation of the alkaline treated pectins in comparison to HMP-R, was strongly restricted. ß-elimination in case of HMP-AL was lower in comparison to HMP-R and CP as a result of the lower initial DM $(59 \%<71 \%)$, and the reaction was further reduced with increasing demethoxylation. ß-Elimination was even lower in LMP-AL than in HMP-AL because of the lower initial DM. These conditions explain the very low total depolymerisation of LMP-AL (least of all samples).

As discussed for HMP-R, the NS side chains of the alkaline treated samples were probably also partly cleaved by thermolysis and some of the NS were degraded.

\subsection{Acidic treated pectins}

Acidic and alkaline treated pectins had similar DM of about $60 \%$ for the HMP and $40 \%$ for the LMP, respectively, but the bulk densities of the acidic treated pectins were much higher than those of the alkaline treated. As a result of previous works about water uptake of samples with similar differences in bulk density (Einhorn-Stoll, Kastner, Hecht, Zimathies, \& Drusch, 2015b) it was expected that the lower water uptake in the acidic treated pectins would be unfavourable for the degradation reactions. In contrast, demethoxylation and, in particular, depolymerisation of the acidic treated pectins were much stronger than those of the alkaline treated. These effects should be based on differences in other molecular parameters.

One difference was the NS content. Side chains had been partly removed during acidic demethoxylation and were separated in the supernatant of the pectin precipitation. The NS content seemed to increase during degradation of acidic treated pectins. This may be explained by the material properties, especially the high bulk density, of the samples in combination with the method of determination of the NS. Strong inter- and intramolecular interactions (mainly hydrogen bonds) are formed during acidic demethoxylation and trapped after drying (Einhorn-Stoll, Hatakeyama, \& Hatakeyama, 2012). They result in a very compact particle structure as shown before in SEM (Einhorn-Stoll, 2017). During thermolysis, the particles absorbed moisture from the environment, softened, swelled and partly even dissolved (Basu et al., 2013), at least at their surface. This improved the water access to the pectin particles and molecules and caused a certain "opening" of the particle structure as well as loosening of the strong intermolecular bonds. These structure alterations later on were able to improve the release of the NS before / during sugar analysis and caused the apparent increase. Nevertheless, also the NS content of the degraded acidic treated pectins was the lowest of all tested samples. 
As a result of the reduced NS content after acidic treatment, more water was available for demethoxylation of the acidic treated samples than in case of the other studied pectins. Indeed, the DM of HMP- and LMP-A decreased quicker and more pronounced than that of any other tested sample. Also the depolymerisation of the acidic treated was the most rapid off all investigated pectins. In principle, ß-elimination at the beginning of the storage was expected to be comparable in acidic and alkaline modified pectins. With increasing storage time and as a result of the more intensive demethoxylation, ß-elimination was stronger reduced in acidic treated pectins (in particular LMP-A) than in alkaline treated and in all other tested pectins. This explains partly the lower increase of a- and b-values (less browning because of less unsaturated uronides) of the acidic treated pectins in comparison to most other samples. Nevertheless, HMP-A and LMP-A showed a considerable browning that, in particular for LMP-A, cannot be explained by the ß-elimination. Obviously, another parallel reaction took place which did not only cause a certain browning but also strong depolymerisation. As a consequence, the degradation of the acidic treated pectins strongly supports the theory of a third depolymerisation reaction beside backbone hydrolysis and ßelimination.

\subsection{Depolymerisation by eliminative decarboxylation}

The additional depolymerisation reaction might be an eliminative decarboxylation as suggested by Einhorn-Stoll \& Kunzek (2009) and as shown in Fig. 11. A hydrogen bond could be transferred to the oxygen of the glycosidic linkage and would allow a simultaneous elimination reaction (arrows in the figure). The reaction products would be $\mathrm{CO}_{2}$ and a $\mathrm{C} 4-\mathrm{C} 5$ unsaturated uronide fragment that later on might form browning products. The reaction requires no water and was found before in particular for pectins after acidic treatment (Einhorn-Stoll \& Kunzek, 2009). In that study it was assumed that the pectin conformation, ${ }^{4} \mathrm{C}_{1}$ or ${ }^{1} \mathrm{C}_{4}$, might have an influence on this reaction, similar to the enhancing effect of ${ }^{4} \mathrm{C}_{1}$ conformation with axial positions of the reacting groups in ß-elimination (Kravtchenko et al., 1992) or to the influence of the conformation on the acidic hydrolysis of glucosides (Moiseev, Khalturinskii, \& Zaikov, 1976; Timell et al., 1965). It is, however, still not possible to examine the conformation of pectins in dry state, and any dissolution would alter the conformation. It seems to be reasonable, instead, that the key factor was the sodium ion content. The decarboxylation reaction requires a free carboxyl group $(-\mathrm{COOH})$ at $\mathrm{C} 6$, and in all pectin samples of this study beside the acidic treated, sodium ions are bound at this position, forming -COONa and preventing this reaction.

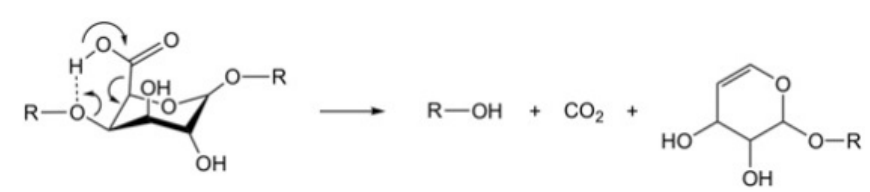

Fig. 11 Suggested mechanism of depolymerisation reaction $X$. The arrows show the possible course of the reaction. 
It is assumed that newly formed free carboxyl groups, resulting from demethoxylation in the course of the degradation, would allow a certain extent of eliminative decarboxylation in all tested pectins. However, the slower and lower the demethoxylation, the less important was the contribution of this reaction to depolymerisation.

\subsection{Final comparison}

A final comparison shall summarize the effects of the different pre-treatments on the thermal degradation of pectins:

- Acidic pre-treatment reduced the high NS content of the CP and, thus, allowed more demethoxylation during storage. The resulting higher number of free carboxyl groups further reduced the limited ß-elimination but intensified depolymerisation by eliminative decarboxylation. The latter reaction was additionally supported by the lack of sodium ions of the modified samples. As a result, the two acidic treated pectins proved to be the least stable of all tested samples.

- Alkaline pre-treatment, in contrast, did not alter the NS content of the CP and, in case of LMP-AL, increased the high sodium ion content. NS cleavage retarded demethoxylation during storage and, indirectly, supported the ß-elimination especially in HMP-AL. Sodium ions on the one hand altered the material properties and increased the water uptake for thermolysis, but on the other hand they inhibited the alternative depolymerisation by eliminative decarboxylation. As a result, $L M P-A L$ was the most stable of all tested pectins. 


\section{Conclusions}

Demethoxylation, cleavage of neutral sugar side chains and depolymerisation by backbone hydrolysis competed for the limited water supply during thermal degradation of dry pectin powder in the climate chamber at $80 \%$ humidity. The alternatively occurring depolymerisation reactions ß-elimination and eliminative decarboxylation required no water.

The presented results show clearly that, under these conditions, the type of the pre-treatments during the modifications of pectins was highly important for the type, extent and velocity of their thermal degradation reactions. The molecular parameters neutral sugar and sodium ion content, altered to different extents during modification, were crucial for the dominating type and kinetic of the degradation. The higher the neutral sugar content, the more water was required for their cleavage, and, due to competitive effects, the less water was available for demethoxylation and backbone hydrolysis. The higher the sodium ion content, the less compact was the pectin structure and the better was the availability of water for these reactions. However, sodium ions were bound to the carboxyl group (-COONa) and prevented depolymerisation by eliminative decarboxylation.

This study confirmed the existence of an additional depolymerisation mechanism by eliminative decarboxylation beside the well-examined reactions backbone hydrolysis and ß-elimination. Further work, especially concerning the analysis of degradation intermediate products, released gases and final reaction products, is necessary in order to confirm and specify the presented results. In particular, the influence of an even more restricted water supply and the role of sodium ions will be the subjects of future investigations.

As a consequence of the presented results, pectin producing / applying companies should know and consider the type of pre-treatment of their pectins, in particular before a longer storage in a warm and humid environment. Pectins demethoxylated by acidic treatments are more sensitive for thermal degradation than pectins demethoxylated by an alkaline treatment in a $\mathrm{pH}$-stat-procedure using sodium hydroxide. Pectins demethoxylated by enzymes are expected to behave comparable to alkaline pre-treated, since also enzymatic demethoxylation mostly is performed by $\mathrm{pH}$-stattechnique using sodium hydroxide. This is just under investigation and will be presented in a following paper. 


\section{Acknowledgements}

The authors are grateful for the financial support of the Deutsche Forschungsgemeinschaft (DFG-project "Structure-depending degradation reactions of pectins and their impact on nonenzymatic browning and technological functionality") (DR 806/4-1). They also would like to thank Jessica Schmidt, Julia Wolff and Antonia Orthmann for the sample preparation and Astrid Kliegel for the support in pectin analysis.

\section{List of abbreviations}
-A acidic treated
$-\mathrm{AL} \quad$ alkaline treated
Ara arabinose
CP commercial pectin
DM degree of methoxylation
DTG differential thermogravimetry
Gal galactose
GalA galacturonic acid
GC galacturonan content
Glu glucose
HMP high-methoxylated pectin
LMP low methoxylated pectin
MW molecular weight
NS neutral sugars
$-R \quad$ reference
Ton extrapolated onset-temperature
$T_{p} \quad$ peak temperature
[ๆ] intrinsic viscosity 


\section{References}

Albersheim, P., Neukom, H., \& Deuel, H. (1960). Splitting of pectin chain molecules in neutral solutions. Archives of Biochemistry and Biophysics, 90, 46-51.

Axelos, M. A. V., \& Branger, M. (1993). The effect of the degree of esterification on the thermal stability and chain conformation of pectins. Food Hydrocolloids, 7(2), 91-102. http://doi.org/10.1016/S0268-005X(09)80161-6

Basu, S., Shivhare, U. S., \& Muley, S. (2013). Moisture adsorption isotherms and glass transition temperature of pectin. Journal of Food Science and Technology, 50, 585-589. http://doi.org/10.1007/s13197-011-0327-y

BeMiller, J. N., \& Doyle, E. R. (1971). Acid-catalyzed hydrolysis of alkyl-a-D-glucopyranosides. Carbohydrate Research, 20, 23-30.

BeMiller, J. N., \& Kumari, G. V. (1972). beta-Elimination in uronic acids: Evidence for an ElcB Mechanism. Carbohydrate Polymers, 25, 419-428.

Blumenkrantz, N, Asboe-Hansen, G. (1973). New method for quantitative determination of uronic acids. Anal. Chem., 54, 484-489.

Bornik, M., \& Kroh, L. W. (2013). D-Galacturonic Acid as a Highly Reactive Compound in Nonenzymatic Browning. 1. Formation of Browning Active Degradation Products. Retrieved from http://pubs.acs.org/doi/pdf/10.1021/jf303855s

Christiaens, S., Van Buggenhout, S., Houben, K., Jamsazzadeh Kermani, Z., Moelants, K. R. N., Ngouémazong, E. D., ... Hendrickx, M. E. G. (2011). Process-Structure-Function Relations of Pectin in Food. Food Research International, 44, 1604-1614. http://doi.org/10.1080/10408398.2012.753029

Cuq, B., Rondet, E., \& Abecassis, J. (2011). Food powders engineering, between knowhow and science: Constraints, stakes and opportunities. Powder Technology, 208(2), 244-251. http://doi.org/10.1016/j.powtec.2010.08.012

Diaz, J. V., Anthon, G. E., \& Barrett, D. M. (2007). Nonenzymatic degradation of citrus pectin and pectate during prolonged heating: Effects of $\mathrm{pH}$, temperature, and degree of methyl esterification. Journal of Agricultural and Food Chemistry, 55, 5131-5136. http://doi.org/10.1021/jf0701483

Einhorn-Stoll, U. (2016). Pectin-water interactions in foods - From powder to gel. Food Hydrocolloids, 1-11. http://doi.org/10.1016/j.foodhyd.2017.05.029

Einhorn-Stoll, U., Benthin, A., Zimathies, A., Görke, O., \& Drusch, S. (2015a). Pectin-water interactions: Comparison of different analytical methods and influence of storage. Food 
Hydrocolloids, 43, 577-583. http://doi.org/10.1016/j.foodhyd.2014.07.013

Einhorn-Stoll, U., Glasenapp, N., \& Kunzek, H. (1996). Modified pectins in whey protein emulsions. Food / Nahrung, 40(2), 60-67. http://doi.org/10.1002/food.19960400203

Einhorn-Stoll, U., Hatakeyama, H., \& Hatakeyama, T. (2012). Influence of pectin modification on water binding properties. Food Hydrocolloids, 27, 494-502.

http://doi.org/10.1016/j.foodhyd.2011.08.019

Einhorn-Stoll, U., Kastner, H., \& Drusch, S. (2014). Thermally induced degradation of citrus pectins during storage - Alterations in molecular structure, colour and thermal analysis. Food Hydrocolloids, 35, 565-575. http://doi.org/10.1016/j.foodhyd.2013.07.020

Einhorn-Stoll, U., Kastner, H., Hecht, T., Zimathies, A., \& Drusch, S. (2015b). Modification and physico-chemical properties of citrus pectin - Influence of enzymatic and acidic demethoxylation. Food Hydrocolloids, 51, 338-345.

http://doi.org/10.1016/j.foodhyd.2015.05.031

Einhorn-Stoll, U., \& Kunzek, H. (2009). The influence of the storage conditions heat and humidity on conformation, state transitions and degradation behaviour of dried pectins. Food Hydrocolloids, 23(3), 856-866. http://doi.org/10.1016/j.foodhyd.2008.05.001

Einhorn-Stoll, U., Kunzek, H., \& Dongowski, G. (2007). Thermal analysis of chemically and mechanically modified pectins. Food Hydrocolloids, 21, 1101-1112.

http://doi.org/10.1016/j.foodhyd.2006.08.004

Fraeye, I., De Roeck, A., Duvetter, T., Verlent, I., Hendrickx, M., \& Van Loey, A. (2007). Influence of pectin properties and processing conditions on thermal pectin degradation. Food Chemistry, 105, 555-563. http://doi.org/10.1016/j.foodchem.2007.04.009

Garna, H., Mabon, N., Nott, K., Wathelet, B., \& Paquot, M. (2006). Kinetic of the hydrolysis of pectin galacturonic acid chains and quantification by ionic chromatography. Food Chemistry, 96, 477484. http://doi.org/10.1016/j.foodchem.2005.03.002

Ibarz, A., Garza, S., \& Pagán, J. (2008). Nonenzymatic browning of selected fruit juices affected by D-galacturonic acid. International Journal of Food Science and Technology, 43, 908-914. http://doi.org/10.1111/j.1365-2621.2007.01541.x

Jayaraman, A., \& Van Buren, J. P. (1972). Browning of galacturonic acid in a model system simulating fruit beverages and white wine. Journal of Agricultural and Food Chemistry, 20(1), 122-124. http://doi.org/10.1021/jf60179a004

Keijbets, M. J. H., \& Pilnik, W. (1974). ß-elimination of pectin in the presence of anions and cations. Carbohydrate Research, 33, 359-362. 
Krall, S. M., \& McFeeters, R. F. (1998). Pectin Hydrolysis: Effect of Temperature, Degree of Methylation, $\mathrm{pH}$, and Calcium on Hydrolysis Rates. Journal of Agricultural and Food Chemistry, 46(1985), 1311-1315. http://doi.org/10.1021/jf970473y

Kravtchenko, T. P., Arnould, I., Voragen, a. G. J., \& Pilnik, W. (1992). Improvement of the selective depolymerization of pectic substances by chemical $\beta$-elimination in aqueous solution. Carbohydrate Polymers, 19, 237-242. http://doi.org/10.1016/0144-8617(92)90075-2

Matveev, Y. I., Grinberg, V. Y., \& Tolstoguzov, V. B. (2000). The plasticizing effect of water on proteins, polysaccharides and their mixtures. Glassy state of biopolymers, food and seeds. Food Hydrocolloids, 14, 425-437. http://doi.org/10.1016/S0268-005X(00)00020-5

Mende, S., Peter, M., Bartels, K., Dong, T., Rohm, H., \& Jaros, D. (2013). Concentration dependent effects of dextran on the physical properties of acid milk gels. Carbohydrate Polymers, 98 , 1389-1396.

Moiseev, Y. V, Khalturinskii, N. A., \& Zaikov, G. E. (1976). The mechanism of the acid-catalysed hydrolysis of glucosides. Carbohydrate Research, 51, 23-37.

Padival, R.A., Ranganna, S., Manjrekar, S. P. (1981). Stability of pectins during storage. Journal of Food Technology, 16, 367-378.

Renard, C. M. G. C., \& Thibault, J. F. (1996). Degradation of pectins in alkaline conditions: Kinetics of demethylation. Carbohydrate Research, 286, 139-150. http://doi.org/10.1016/00086215(96)00056-0

Sajjaanantakul, T., Van Buren, J. P., \& Downing, D. L. (1993). Effect of cations on heat degradation of chelator-soluble carrot pectin. Carbohydrate Polymers, 20, 207-214. http://doi.org/10.1016/0144-8617(93)90152-T

Sila, D.N., Smout, C.Elliot, F. van Loey, A., Hendrickx, M. (2006). Non-enzymatic Depolymerization of Carrot Pectin : Toward a Better Understanding of Carrot Texture During Thermal Processing. Journal of Food Quality, 71(1), E1-E9.

Sugisawa, H., \& Sudo, K. (1969). The thermal degradation of sugars. The initial products of browning reaction in glucose caramel. Canadian Institute of Food Technology, 2(2), 94-96.

Thakur, B. R., Singh, R. K., \& Handa, A. K. (1997). Chemistry and uses of pectin--a review. Critical Reviews in Food Science and Nutrition, 37(906456174), 47-73.

http://doi.org/10.1080/10408399709527767

Thibault, J.-F. (1983). Enzymatic degradation and $\beta$-elimination of the pectic substances in cherry fruits. Phytochemistry, 22(7), 1567-1571. http://doi.org/10.1016/0031-9422(83)80090-9

Timell, T. E., Enterman, W., Spencer, F., \& Solters, E. J. (1965). The Acid Hydrolysis of Glycosides. 
II. Effect of substituents at C-5. Canadian Journal of Chemistry, 43(9), 2296-2304.

http://doi.org/10.1016/S0008-6215(00)82576-8

Tressl, R., Wondrak, G. T., Garbe, L., \& Rewicki, D. (1998). Pentoses and Hexoses as Sources of New Melanoidin-like Maillard Polymers. J Agric Food Chem, 3(1945), 1765-1776. http://doi.org/10.1021/jf970973r

Van Buren, J. P. (1979). The Chemistry of Texture in Fruites and Vegetables. Journal of Texture Studies, 10(1), 1-23. http://doi.org/10.1111/j.1745-4603.1979.tb01305.x

Voragen, A. G. J., Schols, H. A., \& Pilnik, W. (1988). Non-enzymatic browning of oligogalacturonides in apple juice models. Zeitschrift F??r Lebensmittel-Untersuchung Und Forschung, 187, 315-320. http://doi.org/10.1007/BF01454420

Wegener, S., Kaufmann, M., \& Kroh, L. W. (2017). Influence of L-pyroglutamic acid on the color formation process of non-enzymatic browning reactions. Food Chemistry, 232, 450-454. http://doi.org/10.1016/j.foodchem.2017.04.046 